\title{
Rising Temperatures, Human Health, and the Role of Adaptation
}

\author{
David M. Hondula ${ }^{1,2,3}$ • Robert C. Balling $\mathrm{Jr}^{2}{ }^{2}$ Jennifer K. Vanos ${ }^{4} \cdot$ Matei Georgescu $^{2,3}$
}

Published online: 14 June 2015

(C) Springer International Publishing AG 2015

\begin{abstract}
There is near consensus in the scientific community that humans will experience higher future temperatures due to the ongoing accumulation of greenhouse gases in the atmosphere. The human response to this climatic change, particularly if accompanied by a surge in extreme heat events, is a key topic being addressed by scientists across many disciplines. In this article, we review recent (2012-2015) research on human health impacts of observed and projected increases in summer temperature. We find that studies based on projected changes in climate indicate substantial increases in heat-related mortality and morbidity in the future, while observational studies based on historical climate and health records show a decrease in negative impacts during recent warming. The discrepancy between the two groups of studies generally involves how well and how quickly humans can adapt to changes in climate via physiological, behavioral, infrastructural, and/or technological adaptation, and how such adaptation is quantified.
\end{abstract}

This article is part of the Topical Collection on Climate Change and Human Health

Robert C. Balling, Jr.

robert.balling@asu.edu

1 Center for Policy Informatics, Arizona State University, Phoenix, AZ, USA

2 School of Geographical Sciences and Urban Planning, Arizona State University, Tempe, AZ, USA

3 Julie Ann Wrigley Global Institute of Sustainability, Arizona State University, Tempe, AZ, USA

4 Atmospheric Science Research Group, Department of Geosciences, Texas Tech University, Lubbock, TX, USA
Keywords Climate change $\cdot$ Adaptation $\cdot$ Heat $\cdot$ Mortality $\cdot$ Morbidity $\cdot$ Health

\section{Introduction}

Over the past four decades, climate change has emerged as the leading environmental issue being confronted by nations across the planet. There is no doubt that human activities are significantly altering atmospheric composition, particularly by increasing the concentration of long-lived greenhouse gases (LLGHGs). The climatic effect of increased concentrations of LLGHGs has been of interest to the scientific community for more than a century, but this issue has drawn global socioeconomic attention only in recent decades. One of the most robust predictions given the buildup of greenhouse gases is that global temperatures will increase in the future, and indeed over the past 50 to 100 years, there is overwhelming evidence that the planet has warmed overall. The regional, seasonal, and diurnal character of projected future warming is still a matter of considerable debate, but nearly all scientists agree that future decades will be marked by a warming due to anthropogenic activities [1].

Future warming and other climatic changes could present a range of health consequences $[2,3]$. We focus this review on one subset of climate-sensitive health outcomes: those related to high ambient temperature exposure. At the first glance, the relationship between extreme heat and health issues appears straightforward, and yet, the relationship is far more complicated given the ability of humans to adapt to their environs. In discussing this issue, the Intergovernmental Panel on Climate Change (IPCC) provides a definition of adaptation as "the process of adjustment to actual or expected climate and its effects" [4]. It is noteworthy that many of the fastest growing areas of the world are located in hot climates where extreme 
heat events are commonplace [5], clearly illustrating the power of human adaptation to cope with regularly occurring periods of extreme heat.

We examine heat-related morbidity and mortality for several reasons. First, the conceptual pathway linking climate change to heat-health outcomes is direct and obvious: a warmer climate will expose people to higher temperatures assuming no changes in behavior. Second, a wealth of studies exists establishing a positive association between high temperatures and adverse health outcomes. This literature is most well established in developed countries [6-9], but a growing literature documents effects in developing countries as well [10-14]. Furthermore, in some developed countries, extreme heat ranks currently as a leading cause of weather-related deaths $[15,16]$.

Our focus on heat-health impacts is especially critical due to the high confidence expressed in the literature regarding observed and projected temperature increases. It is "virtually certain" that many places around the world have warmed in recent decades [17-19]. The observed increase in globally averaged twentieth century near-surface temperatures has stimulated substantial research asking relevant societal questions: are summers becoming warmer and increasingly extreme; and is this expected to continue in the future as a result of continued emissions of LLGHGs? There is a scientific agreement in reference to the first part of the preceding question, namely, that summers have been warming and are expected to continue doing so [20-23], and this warming is coincident with increasingly frequent and intense heat waves in many locations $[24,25]$. This stems from the increase in mean temperature owing to a shifting summertime probability distribution function. The historical evidence for increasing summertime temperature variability, however, is less clear [26-28]. In addition, assessing the total urban-generated heat impact in combination with warming due to LLGHGs is an important consideration given the rising number of urban dwellers, but is a topic only recently gaining consideration [29-31]. The focus on urban areas is especially germane because of the probable built environment-generated amplification and extension of heat waves and their health impacts [32, 33].

Much of the key observational and modeling evidence needed to draw a conclusion related to the relationship between heat-related health outcomes and climate change, thus, would seem to be in place: we know that people are sensitive to high temperatures; we know that temperatures have been increasing in many locations; and we have a high degree of confidence that these temperature increases will continue or potentially accelerate. These evidence have led scientists and government agencies to express serious concerns about future heat-related health impacts because of a dangerous confluence of these and other (e.g., population growth, aging) factors [12, 34]. In a 2012 report focusing on the United States Midwest region, the Union of Concerned Scientists advocated "aggressive action to reduce heat-trapping emissions from the burning of fossil fuels" citing the health risks posed by increasing temperatures [35]. The 2014 United States National Climate Assessment similarly warned of an "increase in heatrelated deaths" and draws attention to the projected temperature of the hottest summer days by the late twenty-first century [36]. Finally, the Fifth Assessment Report of the IPCC includes heat waves and heat stress in its assessment of Reasons for Concern regarding human influence on climate, listing a "greater likelihood of injury, disease, and death due to more intense heat waves" as the first example of concerns from the health sector [37].

The next section examines the literature reporting observed changes in heat-related mortality and morbidity based on historical records. Next, studies anticipating future heat-related health impacts based on climate projections are reviewed, followed by a discussion of our current understanding of the pathways by which humans may (or may not) be able to adapt to increasing temperatures. We conclude with our own assessment of the state of the recent literature in providing a basis for assessing mankind's ability to adapt to increasing temperatures. To highlight the most recent findings on these topics, this review emphasizes articles published in the period 20122015. To complete "Historical Evidence: Trends in HeatRelated Mortality and Morbidity", "Considering the Future Health Burden of Heat", and "Pathways for Adaptation", we identified an initial set of articles to include in the review by using the following search terms through Web of Science and Google Scholar search engines restricted to peer-reviewed publications: heat, mortality, trend, health, adaptation, and climate. Many articles that quantified the association between temperature and mortality were excluded because they did not focus on how the relationship has evolved or will evolve over time. We employed a snowballing approach in which articles cited in and/or citing the initially identified set of publications were deemed relevant to the topics of each main section of the manuscript.

\section{Historical Evidence: Trends in Heat-Related Mortality and Morbidity}

\section{Methods Employed to Understand Trends}

Measurement of the changes in heat-related mortality and morbidity over time requires multidecadal datasets of both health outcomes and meteorological observations. The specific statistical methods applied by researchers vary, but generally involve the calculation of decade-specific relative risks (RR) of heat-related mortality or morbidity on days considered to present elevated danger. A representative study [38] developed a distributed lag non-linear model relating temperature to mortality for each of nine different decades in the 
1900 s and early 2000 s, reporting both the shape of the temperature-mortality relationship and the decade-specific RR of mortality above a threshold temperature. Some studies with an emphasis on evaluating the effectiveness of heat preparedness strategies report only two time points using a similar experimental design - the temperature effect before and after implementation [39]. An alternative approach to this piecewise examination of the temperature-health relationship is to allow for time-varying coefficients for the effect of heat in statistical models [40].

\section{Observed Changes in Heat-Related Mortality and Morbidity}

There is nearly unanimous reporting of declining sensitivity to heat in the literature we reviewed. In many cases, sensitivity to heat has been found to decline by more than $50 \%$ comparing recent decades to those prior. In New York, the RR of mortality above a threshold temperature declined from greater than 1.30 in the earlier twentieth century to 1.26 in the $1970 \mathrm{~s}$ and 1.09 in the 2000s [38]. Statistically significant differences in late-summer cardiovascular mortality were observed in Seoul, with a nearly two-thirds decline in mortality increases per $1{ }^{\circ} \mathrm{C}$ change in temperature (14.8 to $5.7 \%$ ). The risk of all nonaccidental causes of mortality increased from the 1990s to the 2000s in Seoul, among all age groups and the elderly, howev$\mathrm{er}$, these differences were not statistically significant [41]. In Stockholm, the RR of mortality on extreme heat days for all age groups was estimated to be between 1.00 and 1.12 for the period 2000-2009 versus an RR at or above 1.15 for several prior decades [42].

National-scale studies have examined the USA, Czech Republic, Italy, and Australia. The number of deaths attributed to heat across 105 cities in the USA declined by nearly $63 \%$ between 1987 and 2005 [40]. In the Czech Republic, the mortality impact of heat wave days was found to be declining significantly at a rate of $0.44 \%$ per year from 1986-2009, corresponding to an overall reduction in sensitivity of around $10 \%$ [43]. The heat-related death rate in recent decades in Australia has been approximately twothirds less than that observed in the late nineteenth and early twentieth century [15]. In a study of 16 cities in Italy, the effect among the elderly of $9-12{ }^{\circ} \mathrm{C}$ increases in temperature above city-specific baselines declined from $36.8 \%$ in the period 1998-2002 to $13.3 \%$ in the period 2006-2010 following the implementation of a heat response plan [39].

Reasons offered for the drivers of these declines include increasing availability of air conditioning, the introduction of heat warning systems, coordination of networks of cooling centers, increased healthcare expenditures, and broad-scale epidemiologic transition including life expectancy increases related to reduced sensitivity to infectious diseases $[38,39$, $41,42]$. Formal statistical evaluation of associations between these adaptation mechanisms is largely absent from the recent literature, with a notable exception found by Bobb et al. [40] who reported that in cities with larger increases in air conditioning prevalence in the USA, there was no statistically significant evidence pointing to greater reductions in heat-related mortality.

\section{Historical Evidence: Climate Change Impacts}

The above studies do not specifically examine the impact of climate change on heat-related mortality per se. Our review of the literature revealed only one study aimed at this issue, which investigated the heat mortality response in Stockholm during two periods: 1900-1929 and 1980-2009. The authors concluded that heat-related mortality from 1980-2009 was double the effect that would have been observed in the absence of climate change due to the temperature distribution shifting toward a warmer climate between the two periods [44]. In response to this study, others suggested a contradiction [45] to results previously reported for Stockholm [42], noting significant adaptation over a longer time span. If the present-day population had the same sensitivity to heat as that of the early twentieth century, the weather observed during the period 1980-2009 would have resulted in more than four times the number of observed deaths (2993 versus 689). The response [45] further noted that the number of deaths avoided by adaptation (2304) is significantly larger than the number of deaths attributed to climate change (288).

This exchange $[44,45]$ raises critical concerns about the relative importance of intentional versus unintentional adaptation. Unintentional adaptation to extreme weather events relate to an overall increase in population resilience, whereby health and socioeconomic development may indeed be key drivers of declining sensitivity to heat even though these processes are not directly instituted in response to climate change $[43,45]$. On the other hand, there is a wide suite of adaptation measures implemented in specific response to the threat of extreme heat, where climate change is a potential trigger of such measures. There is limited evidence of direct consideration of the extent to which these intentional and unintentional adaptations contribute to changing sensitivity to heat over time, and parsing out their relative effect is a key challenge. If changing climate is itself a modifier of the relationship between temperature and mortality (e.g., increasing heat wave frequency or severity leads to increasing public awareness and preventative measures), a quantitative approach for disentangling these effects has yet to be established.

\section{Considering the Future Health Burden of Heat}

A complimentary body of literature examines changes in heatrelated mortality and morbidity moving from present to future. 
The majority of these studies are designed around historical health and meteorological data in conjunction with projections of a future climate obtained from global-, regional-, or urbanscale models. The basic framework is to derive a temperaturemortality (or morbidity) relationship based on the historical observations. Then, the historical meteorology is replaced with projections for the future, and a new impact assessment is performed. More comprehensive studies include a range of climate models, greenhouse gas and urbanization forcing scenarios, and anticipated changes in the demographic composition, size, and geography of the population.

Based on fundamental physiological principles $[4,46]$, we can assume that people will acclimatize to new temperatures at varying rates (and to a certain extent). However, many studies produce heat-related mortality projections in the absence of physiological (or other forms of) adaption (e.g., [47-51]), and are discussed in detail in "Results From Projections Without Adaptation". A subset of projection-oriented studies explicitly strives to account for potential adaptation in calculating future impacts (e.g., [52-55]) as discussed in "Projections of HeatHealth Impacts With Adaptation". Quantification of uncertainty in such projections is a considerable challenge, as nearly all steps in making such a calculation introduce some range of confidence. These ranges, when compounded, can become quite large, yet are critical to understand and report as they provide a more comprehensive assessment of plausible outcomes [56].

\section{Results From Projections Without Adaptation}

Nearly all researchers projecting heat-health impacts for the future (without accounting for adaptation) have concluded that heat-related deaths or illnesses will increase. In some cases, the projected increases are staggeringly large, spanning multiple orders of magnitude. Heat-related mortality projections for the 2080s for three cities in the northeastern USA, for example, indicate sixfold to ninefold increases under a higher emission scenario (RCP 8.5) [47]. Similarly, heat-related mortality rates were projected to increase by factors of more than five in a suite of Canadian cities for the period 2071-2090 [48]. Other studies have reported substantial increases in heat-health impacts for heat-related deaths in Italy [49], New York City [57], the United Kingdom [50], the eastern USA [51], and Washington State (USA) [58], ischemic heart disease mortality in Germany [59], multiple causes of hospital admission in Milwaukee, USA [60], and respiratory-related hospital admissions in Southern Europe [61]. Logically, projected increases in heat-health outcomes are greater under higher emission scenarios when compared to lower emission scenarios [e.g., 57]. A study of 12 cities in the USA concluded that 22,000 heat-related deaths would be avoided by the end of the century under a lower emission scenario compared with a higher emission scenario [62].

\section{Projections of Heat-Health Impacts With Adaptation}

Recognizing the importance of considering non-stationarity in the temperature-health relationship [63], a number of methodological approaches to incorporate adaptation into calculations of future health impacts associated with temperature changes have been introduced, as described in Table 1 .

Accounting for potential adaptation in projecting future heat-related health impacts has had a large impact on the quantitative burden reported in several recent studies. In a study of London, accounting for adaptation using the fixed value approach decreased projected future deaths by more than $55 \%$ [52]. Similar results were reported in a study of future impacts in Beirut, Lebanon [71]. A study using a combination of the fixed value and analog city approaches led to the conclusion that even in the presence of adaptation measures, climate mitigation policy would still have a beneficial impact in terms of reducing heat-related (and overall temperature-related) mortality, although the benefits of the mitigation policy were smaller than they would have been in the absence of adaptation [65]. Studies from the USA using methods discounting early heat wave mortality and modeling urban climate changes also report that projections of future heat-related impacts could be scaled back by, in some cases, $40 \%$ or more $[30,53,72]$.

\section{Pathways for Adaptation}

The main types of climate change adaptation related to heat include physiological adaptation (or acclimatization), behavioral, infrastructure, and technological adaptation. Individuals and defined groups within society demonstrate a range of adaptive capacities (a measure of ability to adjust to the potential impacts of climate change [73]), which are based on location, and physical or social vulnerabilities. However, little to no quantitative information concerning the role of adaptation in mitigating the effects of extreme temperatures on health exists, largely due to few real-world datasets on adaptation behaviors [74]. Further, most studies in public health do not directly measure and analyze adaptive behaviors in response to temperature extremes, although some do consider adaptation as a residual explanation for observed changes in mortality over time [74].

Physiological adaptation refers to acclimatization and is broadly defined by the IPCC as a change in functional or morphological traits occurring once or repeatedly (e.g., seasonally), where through short-term acclimatization, the individual maintains performance across a range of environmental conditions [4]. Specific to heat, acclimatization is a relatively quick (days to weeks) and automatic change in human physiology (e.g., increased tolerance to extreme heat through increased blood flow to the periphery, lower resting core temperature, and more efficient sweating) [75, 76]. Limits to 
Table 1 Approaches employed in the literature to incorporate various forms of adaptation into calculations of future heat-related mortality

\begin{tabular}{|c|c|c|}
\hline Type of adaptation method & Explanation/reasoning and examples & References \\
\hline $\begin{array}{l}\text { 1. Fixed value approach } \\
\text { (shifted dose-response relationship) }\end{array}$ & $\begin{array}{l}\text { - Also referred to as the "delta method" } \\
\text { - Adjusts the heat-mortality relationship (including the slope and/or threshold) by } \\
\text { a fixed value based on temperature predictions from climate change scenarios }\end{array}$ & {$[52,64,71]$} \\
\hline 2. Analog city approach & $\begin{array}{l}\text { - Assumes that if a city's climate changes in the future to that of a warmer city, then its } \\
\text { heat-mortality relationship in the future will be similar to that of the warmer city's } \\
\text { - Method has been criticized by some as it assumes stationarity of temperature-mortality } \\
\text { relationships by using past ones to represent future ones } \\
\text { - One could assume that in the future, Philadelphia's (Pennsylvania, US) population } \\
\text { will have the same dose-response relationship as that of the population of a warmer } \\
\text { city like Charlotte (North Carolina, US). }\end{array}$ & {$[54,55,65,66]$} \\
\hline 3. Analog years approach & $\begin{array}{l}\text { - A way of approximating response in a warmer world by assuming that future } \\
\text { acclimatization is based on the dose-response temperature-mortality relationship } \\
\text { only in the hottest summers or years in the past record }\end{array}$ & {$[68-70]$} \\
\hline 4. Remove early heat wave mortality & $\begin{array}{l}\text { - Essentially neglects early heat wave mortality by removing the deaths projected to occur } \\
\text { in the first few days of extreme heat events from the total projected impact } \\
\text { - Implicitly assumes that the population would suffer only under the cumulative effects } \\
\text { - Aims to capture the potential for short-term adaptation but maintains population sensitivity } \\
\text { to particularly severe and prolonged events }\end{array}$ & {$[53]$} \\
\hline 5. Altered urban climate & $\begin{array}{l}\text { - Predicts that the expected change in urban climate associated with adaptation-oriented } \\
\text { technologies results in measurable temperature decreases in urban areas } \\
\text { - Examples include physical alterations to the urban landscape, such as the introduction } \\
\text { of white and/or reflective roofs to reduce air temperature } \\
\text { - Impact of these strategies on heat-health outcomes is measured by considering resulting } \\
\text { changes analogously to considering different global climate scenarios } \\
\text { - No change in the temperature-mortality relationship is assumed or implied }\end{array}$ & {$[30]$} \\
\hline
\end{tabular}

short- and long-term physiological adaptation and human capacity to adapt are presently unknown [77], and major sources of uncertainty exist in understanding how much acclimatization may mitigate the effects of heat on human health $[53,78]$.

Human and societal adaptive capacity, defined as "the ability to adjust potential damage, to take advantage of opportunities, or to respond to consequences" [79] is based on a set of actions that are taken in order to reduce heat-health impacts [74]. The IPCC defines three types of adaptation: anticipatory, planned, and autonomous [77]. These are discussed in the context of behavioral, infrastructure, and technological adaptations in the following texts. These three adaptation types are made up of both "household" (individual) and "community" level adaptation measures as identified by Deschenes [74] and referred to in the following paragraphs at both short- and longtime scales.

Behavioral adaptation is based on a set of actions that households (individuals), communities, and populations can take to adjust to change. These include change in structure of activity (i.e., time allocation responses to extreme temperatures), and geographic mobility. Both are types of anticipatory adaptation, which is an "action that avoids or reduces a climate-change impact" [4]. Few studies find credible opportunities to combine long-term large-scale empirical data on adaptive behaviors with health outcomes [74]; however, some have recently addressed this issue $[40,79]$ by examining the protective effectiveness of air conditioning $(\mathrm{AC})$ against heatrelated mortality. $\mathrm{AC}$ is a commonly utilized and cited behavioral adaptation [80-82]. In one study, increasing use of residential AC alone explained almost $90 \%$ of the decline in heat-related mortality on hot $\left(>32.2^{\circ} \mathrm{C}\right)$ days from 1960 to 2004 [79]. However, contrary conclusions have also been suggested [40].

Infrastructure adaptation aims to reduce the risks to physical and organizational structures that are major societal investments [83], including healthcare systems, roads, and communication systems. This is a planned, or "human-assisted" adaptation, which is proactive and can either adjust the broader system or transform it, with the intent of increasing the capacity of a system (such as community or population) to function at a future temperature [4]. However, a review of 30 articles on "planned adaptation" specific to heat reported inconclusive evidence on the effect, despite the majority of studies reporting mortality/morbidity reductions over time [84].

Sustainability initiatives address planned adaptation for the long-term in both households and communities [74], where urban redesign guidelines and cooling strategies [29, 31, 72, 85-89], preparedness efforts (education, cooling centers [90]), and interventions to decrease the temperatures in aged buildings (e.g., reducing solar gains, insulation and ventilation [91]) are long-term adaptations that reduce individuals' heat exposure. Few studies listed assess potential empirical relationships with health outcomes [30, 72]. Heat-health risks for individuals are ultimately determined by the full suite of variables included in the human energy budget [89], but we observed that most literature focuses exclusively on temperature 
or a temperature-humidity index. A wide range of indices are available for considering all meteorological variables relevant to the human thermal experience that relate to landscape design [92-94], yet little evidence exists that a combination of variables is a better predictor of population-level response than temperature alone [95-97].

The last type of adaptation to heat is technological adaptation, which refers specifically to retrofitting and replacement of existing technologies to adjust to change. Technological adaptation can be anticipatory, planned, or autonomous, and applied at both the household and community levels. Autonomous refers to "incremental changes in the existing system including through the ongoing implementation of extant knowledge and technology in response to the changes in climate experienced" [4]. One example of technological adaptation is the use of heat warning systems [96, 98-100], yet challenges remain when designing these systems [96-98] and effectively issuing warnings [7, 101]. The improvements in efficiency of air conditioning systems is both a planned and anticipatory technological adaptation, where the reduction of electricity usage at minimal costs to households and increased efficiency [102] and the reduction of heat output into the urban fabric [103], are hypothesized to reduce heat-related risks.

\section{Discussion and Conclusions}

The ability of humans to adapt to climate change, and more specifically cope with the health hazards associated with exposure to high temperatures, will almost certainly be a topic that receives continuing attention in the years ahead. Although heat-related morbidity and mortality are small subsets of the total range of possible health impacts associated with climate change, the literature reviewed herein suggests that it is one in need of more investigation. Few connections between climate change and health could be conceptually clearer, and yet there is a considerable contrast in the literature between observational studies that report decreasing heat-related health impacts over time and projection-based studies that report significant anticipated increases in the future (see Table 2). Resolving this discrepancy - to build confidence in the sign of the trend in heat-health impacts moving forward, let alone the magnitude - is challenging. Studies attempting to account for adaptation in projections of future heat-related health impacts have generally reported that adaptation efforts can partially offset expected impacts associated with climate change.

Researchers tackling this area of investigation in the future years have an even wider range of topical, methodological, and geographical approaches and contexts for pursuing such work beyond what we have reviewed herein. First, we note that much of the information on the relationship between temperature and mortality and how it has evolved over time is derived from temperate climates in developed countries. Yet, the majority of the global population growth and urbanization expected in the coming decades will occur in developing countries and hot climates. Even in locations that have been examined in this context, there are additional dimensions to the heat-health relationship that are, for the most part, yet to be incorporated in research considering temporal changes in sensitivity to heat. For example, a growing number of studies document significant intra-city spatial variability in heatrelated health impacts [104-108], and focusing on the cityscale response may miss opportunities to understand more specifically where and why adaptation has occurred or may occur in the future. Similarly, heat-health impacts differ across a range of health outcomes (e.g., cardiovascular mortality, mortality or morbidity related to direct heat exposure) and sub-populations (e.g., age groups, socioeconomic classes), contrasts masked by unstratified analysis for aggregate populations [7, 12, 109]. Examining trends in multiple health outcomes simultaneously is a particularly appealing study design to understand potential adaptation; reductions in heat-related mortality and concurrent increases in hospital admissions for heat-related causes in New York City were suggested as evidence of increased awareness of the hazards of heat [110]. Study designs that include different response functions for various age groups and account for age group-specific population trends are also more useful than examining aggregated populations, because age is an important risk factor for heat, and large changes in the age structure of the population are expected in the coming decades [e.g., 53]. Accounting for possible mortality displacement $[49,111]$ in assessing historical and future impacts has also been largely neglected to date as most literature focuses on outcomes observed in the immediate aftermath of a heat event.

Further consideration of our ability to adapt to rising temperatures raises additional questions about indirect climatesensitive health effects and tradeoffs with other health outcomes that are outside the focus of this review but merit acknowledgment in light of their importance for the development of effective policy, practice, and research. For example, even if humans become fully adapted to high temperatures in terms of direct exposure and health impacts, it is possible that their health may still be negatively affected by rising temperatures as a result of poorer air quality. Projections of future air quality resulting from climate change are difficult to calculate in the face of anticipated technological improvements and emission control policies, and thus the isolated net effect of climate change on air quality, particularly for pollutants beyond ozone (at any spatial scale), is highly uncertain and has high regional variability $[112,113]$. Separately, a number of researchers have investigated the potential "savings" of decreased cold-related morbidity and mortality, and reached differing conclusions regarding whether or not fewer cold-related illnesses or deaths in the future would offset any increases associated with heat $[48,51,57,114]$. Regardless of 
Table 2 A list of recent (2012-2014) studies examining historical trends and/or future projections of heat-related health impacts

\begin{tabular}{|c|c|c|c|c|}
\hline Citation number & Authors & Year published & Study location & Sample of study results \\
\hline \multicolumn{5}{|c|}{ Observed changes in heat-related mortality and morbidity ("Observed Changes in Heat-Related Mortality and Morbidity") } \\
\hline 15 & Coates et al. & 2014 & Australia & $\begin{array}{l}\text { Two-thirds decline in heat-related death rate between late nineteenth } \\
\text { and late twentieth century }\end{array}$ \\
\hline 38 & Petkova et al. & 2014 & New York City, USA & $\begin{array}{l}\text { Decrease in relative risk of mortality from above } 1.30 \text { in early } 1900 \mathrm{~s} \\
\text { to } 1.09 \text { in } 2000 \mathrm{~s}\end{array}$ \\
\hline 39 & Schifano et al. & 2012 & Italy & $\begin{array}{l}\text { Relative risk of mortality among elderly from large temperature increases } \\
\text { declined from } 36.8 \% \text { in } 1998-2002 \text { to } 13.3 \% \text { in } 2006-2010 \text {. }\end{array}$ \\
\hline 40 & Bobb et al. & 2014 & USA & Decrease in heat-attributable deaths of $63 \%$ between 1987 and 2005 \\
\hline 41 & Ha and Kim & 2013 & Seoul, South Korea & $\begin{array}{l}\text { Increase in all-cause heat-related mortality per degree above threshold } \\
\text { from } 4.73 \text { in } 1990 \text { s to } 6.05 \text { in } 2000 \text { s (not statistically significant) }\end{array}$ \\
\hline 42 & Åström et al. & 2013 & Stockholm, Sweden & $\begin{array}{l}\text { Decrease in relative risk of mortality from above } 1.15 \text { before } 2000 \\
\text { to } 1.00-1.12 \text { in period } 2000-2009\end{array}$ \\
\hline 43 & $\begin{array}{l}\text { Kyselý and } \\
\text { Plavcová }\end{array}$ & 2012 & Czech Republic & Decrease in heat-related mortality of $10 \%$ between 1986 and 2009 \\
\hline \multicolumn{5}{|c|}{ Projections of heat-related mortality and morbidity without adaptation ("Results From Projections Without Adaptation") } \\
\hline 47 & Petkova et al. & 2013 & Northeastern USA & $\begin{array}{l}\text { Increase in heat-related mortality to six to nine times present rates in } \\
2080 \text { s using RCP } 8.5 \text {. }\end{array}$ \\
\hline 48 & Martin et al. & 2012 & Canada & $\begin{array}{l}\text { Increase in heat-related mortality to at least four times present rates } \\
\text { in many cities by } 2071-2090 \text { using A2 scenario }\end{array}$ \\
\hline 49 & Morabito et al. & 2012 & Central Italy & $\begin{array}{l}\text { Increase in percent change in mortality per degree above threshold } \\
\text { temperature from } 6.5 \text { to } 9.0 \% \text { by } 2040 \text { in coastal plain cities }\end{array}$ \\
\hline 50 & Hajat et al. & 2014 & United Kingdom & $\begin{array}{l}\text { Mean estimate of heat-related mortality increase by approximately } \\
66,257 \text {, and } 535 \% \text { in } 2020 \text { s, } 2050 \text { s, and } 2080 \text { s, respectively, } \\
\text { from the baseline of around } 2000 \text { deaths }(2000-2009)\end{array}$ \\
\hline 51 & Wu et al. & 2014 & Eastern USA & $\begin{array}{l}\text { Mean absolute excess deaths per year due to heat-related mortality } \\
\text { of } 2397 \text { (range 200-7,807) integrated over RCP } 4.5 \\
\text { and RCP } 8.5 \text { scenarios }\end{array}$ \\
\hline 57 & Li et al. & 2013 & Manhattan, USA & $\begin{array}{l}\text { Increases from } 1980 \text { baseline in heat-related mortality of approximately } \\
22.2,49.4 \text {, and } 91 \% \text { in } 2020 \mathrm{~s}, 2050 \mathrm{~s} \text {, and } 2080 \mathrm{~s} \text {, respectively, } \\
\text { using the A2 scenario }\end{array}$ \\
\hline 58 & Isaksen et al. & 2014 & Washington State, USA & $\begin{array}{l}\text { Increase in heat-related mortality of } 4-22.3 \text { times present rates } \\
\text { by } 2045 \text { among elderly }\end{array}$ \\
\hline 59 & Zacharias et al. & 2014 & Germany & $\begin{array}{l}\text { Significant increase in ischemic heart disease deaths attributable } \\
\text { to heat wave of } 1.9 \text {-fold ( } 685 \text { deaths per year) in 2021-2050, } \\
\text { and 5.1-fold (1801 deaths per year) in 2069-2098 compared } \\
\text { to baseline years of 2000-2010 }\end{array}$ \\
\hline 60 & Li et al. & 2012 & Milwaukee, USA & $\begin{array}{l}\text { Future projection (2059-2075) of higher temperatures on hospital } \\
\text { admissions for five causes of admission and three age groups } \\
\text { indicate large but not statistically significant increase in admissions }\end{array}$ \\
\hline 61 & Åström et al. & 2013 & Europe & $\begin{array}{l}\text { Number of heat-related respiratory hospital admissions projected } \\
\text { to be } 26,000 \text { annually for } 2021-2050 \text { compared with } 11,000 \\
\text { in the reference period of } 1981-2010\end{array}$ \\
\hline 62 & Petkova et al. & 2014 & USA & $\begin{array}{l}\text { Projections of 200,000 heat-related deaths between } 1970 \text { and } 2099 \\
\text { for A2 scenario; 22,553 deaths greater than for B1 scenario }\end{array}$ \\
\hline \multicolumn{5}{|c|}{ Projections of heat-related mortality and morbidity with adaptation ("Projections of Heat-Health Impacts With Adaptation") } \\
\hline 30 & Hondula et al. & 2014 & Maricopa County, USA & $\begin{array}{l}\text { Projected increase in heat-related deaths reduced by nearly two-thirds } \\
\text { for the period 2045-2055 with land cover modifications }\end{array}$ \\
\hline 52 & Jenkins et al. & 2014 & London, England & $\begin{array}{l}\text { Fixed value approach decreases projected future heat-related } \\
\text { deaths by } 55 \%\end{array}$ \\
\hline 53 & Sheridan et al. & 2012 & California, USA & $\begin{array}{l}\text { Projected increases in heat-related mortality decreased by } 37-56 \% \\
\text { for the 2090s after early heat wave mortality removed }\end{array}$ \\
\hline 71 & El-Fadel et al. & 2013 & Beirut, Lebanon & $\begin{array}{l}\text { Projected increase in mortality resulting from increasing temperatures } \\
\text { lowered from } 8.4 \text { to } 2.8 \% \text { for the year } 2095 \text { with change } \\
\text { in threshold temperature }\end{array}$ \\
\hline 72 & Stone et al. & 2014 & USA & $\begin{array}{l}\text { Modifications to vegetative and surface cover offset increases } \\
\text { in heat-related mortality by } 40-99 \% \text { in } 2050 \text { across three cities }\end{array}$ \\
\hline
\end{tabular}

The sample results were selected to be representative of manuscript findings but are not necessarily comprehensive summations of the reviewed studies 
the outcome of the debate around these potential indirect consequences of climate change, we argue that understanding if and how people are able to adapt to heat is an important pursuit. Even if climate change ultimately leads to fewer deaths associated with extreme temperatures (both high and low), there is an opportunity to facilitate even greater reductions in adverse health impacts that bear a large cost for health infrastructure $[114,115]$.

Significant scientific questions of relevance for heat-health adaptation also exist with respect to an important aspect of global-scale climate change: is a change in mean temperature to be accompanied by a change in variance? In the case of heat, this would be a concern as heat wave frequency and intensity could increase beyond what would be expected simply as a result of overall warming. The scientific community is divided on this matter to date, with one camp suggesting an observed increase in variance and pointing towards similar impacts in the future [20-23] and the opposing camp suggesting such conclusions are incorrect [26], and instead, are artifacts of inappropriate calculations of higher order moments $[27,28]$. Disproportionate societal impacts due to extremes [116] require an improved understanding of historical changes to serve as a baseline for the provision of projected alteration in future climate variability. That contemporary modeling systems have important deficiencies in their ability to appropriately simulate historical climate variability [117] points to key physical processes that require further refinement (e.g., landatmosphere coupling, cloud treatment).

What is most clear from our review is that the evidence and research methods to determine conclusively whether and to what extent heat-related morbidity and mortality will be impacted by climate change are largely absent. The literature related to this topic appearing in journals with an epidemiological, biometeorological, and/or climatological emphasis almost exclusively considers statistical associations and trends. Our understanding of the causal mechanisms of both heat exposure and adaptation, in any of its many forms, is lacking. With few exceptions [80, 118], we have little evidence of the actual heat exposure of individuals when high temperature events occur, the activities and behaviors undertaken by individuals at risk, the extent to which those actions lessen exposure, and the likelihood that such options will remain available in the future [74]. Systematic and coordinated evaluation of climate-health intervention strategies, like that proposed by the Building Resilience Against Climate Effects framework of the United States Centers for Disease Control and Prevention [119], will be instrumental in closing this large knowledge gap.

The historical evidence concerning heat-related mortality and morbidity relating human capacity to adapt to climate change is encouraging, as the public health burden associated with heat has declined in many locales experiencing warming over the same period. Yet health practitioners, researchers, and policymakers should not take this evidence as a guarantee that there is little concern for the future. Some adaptation measures may be decreasingly effective as physiological and technological limits are approached. Other adaptation measures require sustained effort and coordination to be, or become, effective. We conclude that climate change need not be the sole motivating factor for evaluating heat-health impacts over time and the effectiveness of different adaptation strategies: heat continues to exert a preventable public health burden in cities across the globe. By directing our research efforts to best understand how reduction in heat mortality and morbidity can be achieved, we have the opportunity to improve societal welfare and eliminate unnecessary health consequences of extreme weather - even in a hotter future.

Acknowledgments D. Hondula was supported by the Virginia G. Piper Health Policy Informatics Initiative at Arizona State University and the National Science Foundation under grant number BCS-1026865, Central Arizona-Phoenix Long-Term Ecological Research (CAP LTER). M. Georgescu was supported by the National Science Foundation grant number EAR-1204774. The authors thank two anonymous reviewers whose feedback substantially improved this manuscript and B. Hondula for the assistance in editing the final draft.

Conflict of Interest The authors declare that they have no competing interests.

\section{References}

1. IPCC. Climate change 2013: the physical science basis. Intergovernmental panel on climate change. Cambridge: Cambridge University Press; 2013.

2. Patz JA, Campbell-Lendrum D, Holloway T, Foley JA. Impact of regional climate change on human health. Nature. 2005;438(7066):310-7.

3. McMichael AJ, Woodruff RE, Hales S. Climate change and human health: present and future risks. Lancet. 2006;367(9513): 859-69.

4. IPCC, Barros VR, Field CB, Dokken DJ, Mastrandrea MD, Mach KJ, et al. In: Mastrandrea PR, White LL, editors. Climate Change 2014: impacts, adaptation, and vulnerability. Part B: regional aspects. Contribution of working group II to the fifth assessment report of the intergovernmental panel on climate change. Cambridge: Cambridge University Press; 2014. p. 688.

5. Birch EL, Wachter SM. City in the twenty-first century: global urbanization. Philadelphia: University of Pennsylvania Press; 2011.

6. Breitner S, Wolf K, Devlin RB, Diaz-Sanchez D, Peters A, Schneider A. Short-term effects of air temperature on mortality and effect modification by air pollution in three cities of Bavaria, Germany: a time-series analysis. Sci Total Environ. 2014;485:4961.

7. Harlan SL, Chowell G, Yang S, Petitti DB, Morales Butler EJ, Ruddell BL, et al. Heat-related deaths in hot cities: estimates of human tolerance to high temperature thresholds. Int J Environ Res Public health. 2014;11(3):3304-26.

8. Hondula DM, Davis RE. The predictability of high-risk zones for heat-related mortality in seven US cities. Nat Hazards. 2014;74(2): $771-88$. 
9. Petralli M, Morabito M, Cecchi L, Crisci A, Orlandini S. Urban morbidity in summer: ambulance dispatch data, periodicity and weather. Cent Eur J Med. 2012;7(6):775-82.

10. Egondi T, Kyobutungi C, Kovats S, Muindi K, Ettarh R, Rocklöv $\mathrm{J}$. Time-series analysis of weather and mortality patterns in Nairobi's informal settlements. Global Health Action. 2012;5.

11. Bai L, Ding G, Gu S, Bi P, Su B, Qin D, et al. The effects of summer temperature and heat waves on heat-related illness in a coastal city of China, 2011-2013. Environ Res. 2014;132:212-9.

12. Burkart K, Breitner S, Schneider A, Khan MMH, Krämer A, Endlicher W. An analysis of heat effects in different subpopulations of Bangladesh. Int J Biometeorol. 2014;58(2):227-37.

13. Diboulo E, Sie A, Rocklöv J, Niamba L, Ye M, Bagagnan C, Sauerborn R. Weather and mortality: a 10 year retrospective analysis of the Nouna Health and Demographic Surveillance System, Burkina Faso. Global Health Action. 2012;5.

14. Zeng W, Lao X, Rutherford S, Xu Y, Xu X, Lin H, et al. The effect of heat waves on mortality and effect modifiers in four communities of Guangdong Province, China. Sci Total Environ. 2014;482: 214-21.

15. Coates L, Haynes K, O’Brien J, McAneney J, de Oliveira FD. Exploring 167 years of vulnerability: an examination of extreme heat events in Australia 1844-2010. Environ Sci Pol. 2014;42:33-44.

16. Berko J, Ingram DD, Saha S, Parker JD. Deaths attributed to heat, cold, and other weather events in the United States, 2006-2010. Natl Health Stat Rep. 2014;76:1-16.

17. Fischer EM, Rajczak J, Schär C. Changes in European summer temperature variability revisited. Geophys Res Lett. 2012;39(19).

18. Lee JW, Hong SY, Chang EC, Suh MS, Kang HS. Assessment of future climate change over East Asia due to the RCP scenarios downscaled by GRIMs-RMP. Clim Dyn. 2014;42(3-4):733-47.

19. Hartmann DL, Klein Tank AMG, Rusticucci M, Alexander LV, Brönnimann S, Charabi Y, et al. Observations: atmosphere and surface. In: Stocker TF, Qin D, Plattner G-K, Tignor M, Allen SK, Boschung J, Nauels A, Xia Y, Bex V, Midgley PM, editors. Climate change 2013: the physical science basis. Contribution of working group I to the fifth assessment report of the intergovernmental panel on climate change. Cambridge: Cambridge University Press; 2013.

20. Coumou D, Robinson A. Historic and future increase in the global land area affected by monthly heat extremes. Environ Res Lett. 2013;8(3):034018.

21. Donat MG, Alexander LV. The shifting probability distribution of global daytime and night-time temperatures. Geophys Res Lett. 2012;39(14).

22. Hansen J, Sato M, Ruedy R. Perception of climate change. Proc Natl Acad Sci. 2012;109(37):E2415-23.

23. Rahmstorf $\mathrm{S}$, Coumou D. Increase of extreme events in a warming world. Proc Natl Acad Sci U S A. 2011;108:17905-9.

24. Shevchenko O, Lee H, Snizhko S, Mayer H. Long-term analysis of heat waves in Ukraine. Int J Climatol. 2014;34(5):1642-50.

25. Smith TT, Zaitchik BF, Gohlke JM. Heat waves in the United States: definitions, patterns, and trends. Clim Chang. 2013;118(3-4):811-25.

26. Huntingford C, Jones PD, Livina VN, Lenton TM, Cox PM. No increase in global temperature variability despite changing regional patterns. Nature. 2013;500(7462):327-30.

27. Katz RW, Craigmile PF, Guttorp P, Haran M, Sansó B, Stein ML. Uncertainty analysis in climate change assessments. Nat Clim Chang. 2013;3(9):769-71.

28. Rhines A, Huybers P. Frequent summer temperature extremes reflect changes in the mean, not the variance. Proc Natl Acad Sci U S A. 2013;110:E546.

29. Georgescu M, Moustaoui M, Mahalov A, Dudhia J. Summer-time climate impacts of projected megapolitan expansion in Arizona. Nat Clim Chang. 2013;3(1):37-41.
30. Hondula DM, Georgescu M, Balling RC. Challenges associated with projecting urbanization-induced heat-related mortality. Sci Total Environ. 2014;490:538-44.

31. Georgescu M, Morefield PE, Bierwagen BG, Weaver CP. Urban adaptation can roll back warming of emerging megapolitan regions. Proc Natl Acad Sci. 2014;111(8):2909-14.

32. Li D, Bou-Zeid E. Synergistic interactions between urban heat islands and heat waves: the impact in cities is larger than the sum of its parts*. J Appl Meteorol Climatol. 2013;52(9):2051-64.

33. Kershaw SE, Millward AA. A spatio-temporal index for heat vulnerability assessment. Environ Monit Assess. 2012;184(12): 7329-42.

34. Lissner TK, Holsten A, Walther C, Kropp JP. Towards sectoral and standardised vulnerability assessments: the example of heatwave impacts on human health. Clim Chang. 2012;112(3-4): 687-708.

35. Perera EM, Sanford T, White-Newsome JL, Kalkstein LS, Vanos JK, Weir K. Heat in the Heartland: 60 Years of Warming in the Midwest. Union of concerned scientists. 2012.

36. Luber G, Knowlton K, Balbus J, Frumkin H, Hayden M, Hess J, et al. Ch. 9: human health. Climate change impacts in the United States: the third national climate assessment. Melillo JM, Richmond T(TC), Yohe GW, editors, U.S. Glob Chang Res Program. 2014;220-256. doi:10.7930/J0PN93H5.

37. IPCC. Summary for policymakers. In: Field CB, Barros VR, Dokken DJ, Mach KJ, Mastrandrea MD, Bilir TE, Chatterjee M, Ebi KL, Estrada YO, Genova RC, Girma B, Kissel ES, Levy AN, MacCracken S, Mastrandrea PR, White LL, editors. Climate change 2014: impacts, adaptation, and vulnerability. Part A: global and sectoral aspects. Contribution of working group II to the fifth assessment report of the intergovernmental panel on climate change. Cambridge: Cambridge University Press; 2014. p. 1-32.

38. Petkova EP, Gasparrini A, Kinney PL. Heat and mortality in New York City since the beginning of the 20th century. Epidemiology (Cambridge, Mass). 2014;25(4):554-60.

39. Schifano P, Leone M, De Sario M, de'Donato F, Bargagli AM, D'Ippoliti D, et al. Changes in the effects of heat on mortality among the elderly from 1998-2010: results from a multicenter time series study in Italy. Environ Health. 2012;11(1):58.

40. Bobb JF, Peng RD, Bell ML, Dominici F. Heat-related mortality and adaptation to heat in the United States. Environ Health Perspect. 2014;122(8):811.

41. Ha J, Kim H. Changes in the association between summer temperature and mortality in Seoul, South Korea. Int J Biometeorol. 2013;57(4):535-44.

42. Åström DO, Forsberg B, Edvinsson S, Rocklöv J. Acute fatal effects of short-lasting extreme temperatures in Stockholm, Sweden: evidence across a century of change. Epidemiology. 2013;24(6):820-9.

43. Kyselý J, Plavcová E. Declining impacts of hot spells on mortality in the Czech Republic, 1986-2009: adaptation to climate change? Clim Chang. 2012;113(2):437-53.

44. Åström DO, Forsberg B, Ebi KL, Rocklöv J. Attributing mortality from extreme temperatures to climate change in Stockholm, Sweden. Nat Clim Chang. 2013;3(12):1050-4.

45. Knappenberger P, Michaels P, Watts A. Adaptation to extreme heat in Stockholm County, Sweden. Nat Clim Chang. 2014;4(5):302-3.

46. Parsons K. Human thermal environments: the effects of hot, moderate, and cold environments on human health, comfort, and performance. Boca Raton: CRC+Press; 2014.

47. Petkova EP, Horton RM, Bader DA, Kinney PL. Projected heatrelated mortality in the US urban northeast. Int J Environ Res Public Health. 2013;10(12):6734-47.

48. Martin SL, Cakmak S, Hebbern CA, Avramescu ML, Tremblay N. Climate change and future temperature-related mortality in 15 Canadian cities. Int J Biometeorol. 2012;56(4):605-19. 
49. Morabito M, Crisci A, Moriondo M, Profili F, Francesconi P, Trombi G, et al. Air temperature-related human health outcomes: current impact and estimations of future risks in Central Italy. Sci Total Environ. 2012;441:28-40.

50. Hajat S, Vardoulakis S, Heaviside C, Eggen B. Climate change effects on human health: projections of temperature-related mortality for the UK during the 2020s, 2050s and 2080s. J Epidemiol Community Health. 2014;68(7):641-8.

51. Wu J, Zhou Y, Gao Y, Fu JS, Johnson BA, Huang C, et al. Estimation and uncertainty analysis of impacts of future heat waves on mortality in the eastern United States. Environ Health Perspect. 2014;122(1):10.

52. Jenkins K, Hall J, Glenis V, Kilsby C, McCarthy M, Goodess C, et al. Probabilistic spatial risk assessment of heat impacts and adaptations for London. Clim Chang. 2014;124(1-2):105-17.

53. Sheridan SC, Allen M, Lee CC, Kalkstein LS. Future heat vulnerability in California, Part II: projecting future heat-related mortality. Clim Chang. 2012;115(2):311-26.

54. Knowlton K, Lynn B, Goldberg RA, Rosenzweig C, Hogrefe C, Rosenthal JK, et al. Projecting heat-related mortality impacts under a changing climate in the New York City region. Am J Public Health. 2007;97:2028-34. doi:10.2105/AJPH.2006.102947.

55. Kinney PL, O'Neill MS, Bell ML, Schwartz J. Approaches for estimating effects of climate change on heat-related deaths: challenges and opportunities. Environ Sci Pol. 2008;11(1):87-96.

56. Gosling SN, McGregor GR, Lowe JA. The benefits of quantifying climate model uncertainty in climate change impacts assessment: an example with heat-related mortality change estimates. Clim Chang. 2012;112(2):217-31.

57. Li T, Horton RM, Kinney PL. Projections of seasonal patterns in temperature-related deaths for Manhattan, New York. Nat Clim Chang. 2013;3(8):717-21.

58. Isaksen TB, Yost M, Hom E, Fenske R. Projected health impacts of heat events in Washington State associated with climate change. Rev Environ Health. 2014;29(1-2):119-23.

59. Zacharias S, Koppe C, Mücke HG. Climate change effects on heat waves and future heat wave-associated IHD mortality in Germany. Climate. 2014;3(1):100-17.

60. Li B, Sain S, Mearns LO, Anderson HA, Kovats S, Ebi KL, et al. The impact of extreme heat on morbidity in Milwaukee, Wisconsin. Clim Chang. 2012;110(3-4):959-76.

61. Åström C, Orru H, Rocklöv J, Strandberg G, Ebi KL, Forsberg B. Heat-related respiratory hospital admissions in Europe in a changing climate: a health impact assessment. BMJ Open. 2013;3(1): e001842.

62. Petkova EP, Bader DA, Anderson GB, Horton RM, Knowlton K, Kinney PL. Heat-related mortality in a warming climate: projections for 12 US cities. Int J Environ Res Public Health. 2014;11(11):11371-83.

63. Rocklöv J, Ebi KL. High dose extrapolation in climate change projections of heat-related mortality. J Agric Biol Environ Stat. 2012;17(3):461-75.

64. Gosling SN, McGregor GR, Lowe JA. Climate change and heatrelated mortality in six cities Part 2: climate model evaluation and projected impacts from changes in the mean and variability of temperature with climate change. Int J Biometeorol. 2009;53(1): 31-51.

65. Mills D, Schwartz J, Lee M, Sarofim M, Jones R, Lawson M, et al. Climate change impacts on extreme temperature mortality in select metropolitan areas in the United States. Clim Chang. 2013:1-13.

66. Kalkstein LS, Greene JS, Mills DM, Perrin AD, Samenow JP, Cohen JC. Analog European heat waves for US cities to analyze impacts on heat-related mortality. Bull Am Meteorol Soc. 2008;89(1):75-85.

67. Gosling SN, Lowe JA, McGregor GR, Pelling M, Malamud BD. Associations between elevated atmospheric temperature and human mortality: a critical review of the literature. Clim Chang. 2009;92(3-4):299-341.

68. Hayhoe K, Cayan D, Field CB, Frumhoff PC, Maurer EP, Miller NL, et al. Emissions pathways, climate change, and impacts on California. Proc Natl Acad Sci U S A. 2004;101(34):12422-7.

69. Huang C, Barnett AG, Wang X, Vaneckova P, FitzGerald G, Tong $\mathrm{S}$. Projecting future heat-related mortality under climate change scenarios: a systematic review. Environ Health Perspect. 2011.

70. Cheng CS, Campbell M, Li Q, Li G, Auld H, Day N, et al. Differential and combined impacts of extreme temperatures and air pollution on human mortality in south-central Canada. Part II: future estimates. Air Qual Atmos Health. 2009;1(4): 223-35.

71. El-Fadel M, Ghanimeh S. Climate change and temperature rise in the Greater Beirut Area: implications on heat-related premature mortality. Reg Environ Chang. 2013;13(5):1059-67.

72. Stone Jr B, Vargo J, Liu P, Habeeb D, DeLucia A, Trail M, et al. Avoided heat-related mortality through climate adaptation strategies in three US cities. PLoS One. 2014;9(6):e100852.

73. Füssel HM (2010). Review and quantitative analysis of indices of climate change exposure, adaptive capacity, sensitivity, and impacts.

74. Deschenes O. Temperature, human health, and adaptation: a review of the empirical literature. Energy Econ. 2014;46:606-19.

75. Gosling SN, Bryce EK, Dixon PG, Gabriel KM, Gosling EY, Hanes JM, et al. A glossary for biometeorology. Int J Biometeorol. 2014;58(2):277-308.

76. Nadel E. Problems with temperature regulation during exercise. New York: Academic Press, Inc; 1977.

77. Smith KR, Woodward A, Campbell-Lendrum D, Chadee DD, Honda Y, Liu Q, et al. Human health: impacts, adaptation, and co-benefits. In: Field CB, Barros VR, Dokken DJ, Mac KJ, Mastrandrea MD, Bilir TE, et al., editors. Climate change 2014: impacts, adaptation, and vulnerability. Part A: global and sectoral aspects. Contribution of working group II to the fifth assessment report of the intergovernmental panel on climate change. Cambridge: Cambridge University Press; 2014. p. 709-54.

78. Honda Y, Kondo M, McGregor G, Kim H, Guo YL, Hijoka Y, et al. Heat-related mortality risk model for climate change impact projection. Environ Health Prev Med. 2014;19(1):56-63.

79. Barreca A, Clay K, Deschenes O, Greenstone M, Shapiro JS. Adapting to climate change: the remarkable decline in the US temperature-mortality relationship over the 20th century (No. w18692). Natl Bur Econ Res. 2013.

80. Sampson HR, Gronlund CJ, Buxton MA, Catalano L, WhiteNewsome JL, Conlon KC, et al. Staying cool in a changing climate: reaching vulnerable populations during heat events. Glob Environ Chang. 2013;23(2):475-84.

81. Saman W, Boland J, Pullen S, de Dear RJ, Soebarto V, Miller WF, et al. A framework for adaptation of Australian households to heat waves. Natl Clim Chang Adapt Res Facil. 2013.

82. Akompab DA, Bi P, Williams S, Grant J, Walker IA, Augoustinos $M$. Heat waves and climate change: applying the health belief model to identify predictors of risk perception and adaptive behaviours in Adelaide, Australia. Int J Environ Res Public Health. 2013;10(6):2164-84.

83. Cutter SL, Solecki W, Bragado N, Carmin J, Fragkias M, Ruth M. Ch. 11: urban systems, infrastructure, and vulnerability. Climate change impacts in the United States: the third national climate assessment. Melillo JM, Richmond T(T.C.), Yohe GW, editors., U.S. Glob Chang Res Program. 2014:282-296. doi:10.7930/ J0F769GR.

84. Boeckmann M, Rohn I. Is planned adaptation to heat reducing heat-related mortality and illness? A systematic review. BMC Public Health. 2014;14(1):1112. 
85. Georgescu M, Mahalov A, Moustaoui M. Seasonal hydroclimatic impacts of Sun Corridor expansion. Environ Res Lett. 2012;7(3): 034026.

86. Stone B, Vargo J, Habeeb D. Managing climate change in cities: will climate action plans work? Landsc Urban Plan. 2012;107(3): 263-71.

87. Matzarakis A, Endler C. Climate change and thermal bioclimate in cities: impacts and options for adaptation in Freiburg, Germany. Int J Biometeorol. 2010;54(4):479-83.

88. Brown RD, Vanos JK, Kenny NA, Lenzholzer S. Designing urban parks that ameliorate the effects of climate change. Landsc Urban Plan. 2015. doi:10.1016/j.landurbplan.2015.02.006.

89. Vanos JK, Warland JS, Gillespie TJ, Slater GA, Brown RD, Kenny RD. Human energy budget modeling in urban parks in Toronto and applications to emergency heat stress preparedness. J Appl Meteorol Climatol. 2012;51(9):1639-53.

90. Kravchenko J, Abernathy AP, Fawzy M, Lyerly HK. Minimization of heatwave morbidity and mortality. Am J Prev Med. 2013;44(3):274-82.

91. Porritt SM, Cropper PC, Shao L, Goodier CI. Ranking of interventions to reduce dwelling overheating during heat waves. Energy Build. 2012;55:16-27.

92. Park S, Tuller SE, Jo M. Application of universal thermal climate index (UTCI) for microclimatic analysis in urban thermal environments. Landsc Urban Plan. 2014;125:146-55.

93. Nastos PT, Matzarakis A. The effect of air temperature and human thermal indices on mortality in Athens, Greece. Theor Appl Climatol. 2012;108(3-4):591-9.

94. Vanos JK, Warland JS, Gillespie TJ, Kenny NA. Thermal comfort modelling of body temperature and psychological variations of a human exercising in an outdoor environment. Int J Biometeorol. 2012;56(1):21-32.

95. Urban A, Kyselý J. Comparison of UTCI with other thermal indices in the assessment of heat and cold effects on cardiovascular mortality in the Czech Republic. Int J Environ Res Public Health. 2014;11(1):952-67.

96. Zhang K, Rood RB, Michailidis G, Oswald EM, Schwartz JD, Zanobetti A, et al. Comparing exposure metrics for classifying 'dangerous heat' in heat wave and health warning systems. Environ Int. 2012;46:23-9.

97. Hajat S, Sheridan SC, Allen MJ, Pascal M, Laaidi K, Yagouti A, et al. Heat-health warning systems: a comparison of the predictive capacity of different approaches to identifying dangerously hot days. Am J Public Health. 2010;100(6):1137.

98. Guo Y, Barnett AG, Tong S. High temperatures-related elderly mortality varied greatly from year to year: important information for heat-warning systems. Sci Rep. 2012;2.

99. Hondula DM, Vanos JK, Gosling SN. The SSC: a decade of climate - health research and future directions. Int J Biometeorol. 2014;58(2):109-20.

100. Åström C, Ebi KL, Langner J, Forsberg B. Developing a heatwave early warning system for Sweden: evaluating sensitivity of different epidemiological modelling approaches to forecast temperatures. Int J Environ Res Public Health. 2014;12(1):254-67.

101. Guirguis K, Gershunov A, Tardy A, Basu R. The impact of recent heat waves on human health in California. J Appl Meteorol Climatol. 2014;53(1):3-19.

102. Chua KJ, Chou SK, Yang WM, Yan J. Achieving better energyefficient air conditioning - a review of technologies and strategies. Appl Energy. 2013;104:87-104.
103. Salamanca F, Georgescu M, Mahalov A, Moustaoui M, Wang M. Anthropogenic heating of the urban environment due to air conditioning. J Geophys Res Atmos. 2014;119(10):5949-65.

104. Harlan SL, Declet-Barreto JH, Stefanov WL, Petitti DB. Neighborhood effects on heat deaths: social and environmental predictors of vulnerability in Maricopa County, Arizona. Environ Health Perspect. 2012;121(2):197-204.

105. Goggins WB, Ren C, Ng E, Yang C, Chan EY. Effect modification of the association between meteorological variables and mortality by urban climatic conditions in the tropical city of Kaohsiung, Taiwan. Geospat Health. 2013;8(1):37-44.

106. Hondula DM, Barnett AG. Heat-related morbidity in Brisbane, Australia: spatial variation and area-level predictors. Environ Health Perspect. 2014;122(8):831.

107. Hondula DM, Davis RE, Saha MV, Wegner CR, Veazey ML. Geographic dimensions of heat-related mortality in seven U.S. Cities. Environ Res. 2015. in press.

108. Maier G, Grundstein A, Jang W, Li C, Naeher LP, Shepherd M. Assessing the performance of a vulnerability index during oppressive heat across Georgia, United States. Weather Clim Soc. 2014;6(2):253-63.

109. Page LA, Hajat S, Kovats RS, Howard LM. Temperature-related deaths in people with psychosis, dementia and substance misuse. Br J Psychiatry. 2012;200(6):485-90.

110. Sheridan SC, Lin S. Assessing variability in the impacts of heat on health outcomes in New York City over time, season, and heatwave duration. EcoHealth. 2014:1-14.

111. Saha MV, Davis RE, Hondula DM. Mortality displacement as a function of heat event strength in 7 US cities. Am J Epidemiol. 2014;179(4):467-74.

112. Tai AP, Mickley LJ, Jacob DJ. Impact of 2000-2050 climate change on fine particulate matter (PM 2.5) air quality inferred from a multi-model analysis of meteorological modes. Atmos Chem Phys. 2012;12(23):11329-37.

113. Trail M, Tsimpidi AP, Liu P, Tsigaridis K, Rudokas J, Miller P, et al. Sensitivity of air quality to potential future climate change and emissions in the United States and major cities. Atmos Environ. 2014;94:552-63.

114. Lin S, Hsu WH, Van Zutphen AR, Saha S, Luber G, Hwang SA. Excessive heat and respiratory hospitalizations in New York State: estimating current and future public health burden related to climate change. Environ Health Perspect. 2012;120(1):1571-7.

115. Knowlton K, Rotkin-Ellman M, King G, Margolis HG, Smith D, Solomon G, et al. The 2006 California heat wave: impacts on hospitalizations and emergency department visits. Environ Health Perspect. 2009;117(1):61-7.

116. Schär C, Vidale PL, Lüthi D, Frei C, Häberli C, Liniger MA, et al. The role of increasing temperature variability in European summer heatwaves. Nature. 2004;427(6972):332-6.

117. Vidale PL, Lüthi D, Wegmann R, Schär C. European summer climate variability in a heterogeneous multi-model ensemble. Clim Chang. 2007;81(1):209-32.

118. Kuras ER, Hondula DM, Brown-Saracino J. Heterogeneity in individually experienced temperatures (IETs) within an urban neighborhood: insights from a new approach to measuring heat exposure. Int J Biometeorol. 2015:1-10.

119. Marinucci GD, Luber G, Uejio CK, Saha S, Hess JJ. Building resilience against climate effects - a novel framework to facilitate climate readiness in public health agencies. Int J Environ Res Public Health. 2014;11(6):6433-58. 